\title{
Clustering of Metabolic Syndrome Components Attenuates Coronary Plaque Regression During Intensive Statin Therapy in Patients With Acute Coronary Syndrome - The JAPAN-ACS Subanalysis Study -
}

Hiroaki Takashima, MD; Yukio Ozaki, MD; Takeshi Morimoto, MD; Takeshi Kimura, MD; Takafumi Hiro, MD; Katsumi Miyauchi, MD; Yoshihisa Nakagawa, MD; Masakazu Yamagishi, MD; Hiroyuki Daida, MD; Tomofumi Mizuno, MD; Kenji Asai, MD; Yasuo Kuroda, MD;

Takashi Kosaka, MD; Yasushi Kuhara, MD; Akiyoshi Kurita, MD; Kazuyuki Maeda, MD; Tetsuya Amano, MD; Masunori Matsuzaki, MD for the JAPAN-ACS Investigators

\begin{abstract}
Background: The JAPAN-ACS (Japan Assessment of Pitavastatin and Atorvastatin in Acute Coronary Syndrome) trial showed that intensive statin therapy could induce significant coronary plaque regression in acute coronary syndrome (ACS). We evaluated the impact of metabolic syndrome (MetS) and its components on coronary plaque regression in the JAPAN-ACS patients.
\end{abstract}

Methods and Results: Serial intravascular ultrasound measurements over 8-12 months were performed in 242 ACS patients receiving pitavastatin or atorvastatin. Patients were divided into groups according to the presence of MetS or the number of MetS components. Although the percent change in plaque volume (\%PV) was not significantly different between the MetS $(n=119)$ and non-MetS $(n=123)$ groups $(P=0.50)$, it was significantly associated with an increasing number of MetS components (component $0:-24.0 \%, n=7$; components 1 : $-20.8 \%, n=31$; components 2: $-16.1 \%, n=69$; components $3:-18.7 \%, n=83$; components $4:-13.5 \%, n=52 ; P=0.037$ for trend). The percent change in body mass index (\%BMI) significantly correlated with \%PV $(r=0.15, P=0.021)$, especially in the MetS components 4 group ( $r=0.35, P=0.017)$. In addition, \%BMI was an independent predictor of plaque regression after adjustment for the changes of low- and high-density lipoprotein cholesterol, triglycerides and $\mathrm{HbA}_{1 \mathrm{c}}$.

Conclusions: The clustering of MetS components, but not the presence of MetS itself, could attenuate coronary plaque regression during intensive statin therapy in ACS patients. Therefore, to achieve a greater degree of plaque regression, it is necessary to treat to each MetS component and use lifestyle modification. (Circ $J$ 2012; 76: 2840-2847)

Key Words: Acute coronary syndrome; Intravascular ultrasound; Metabolic syndrome components; Plaque; Statins

$\mathbf{M}$ etabolic syndrome (MetS) is characterized by the clustering of several components, such as abdominal obesity, hyperglycemia, low level of high-density lipoprotein cholesterol (HDL-C), impaired glucose tolerance, and hypertension. It has been reported that MetS is a critical cardiovascular risk and is associated with increased incidence of atherosclerotic cardiovascular events and mortality. ${ }^{1-3}$ Recurrent cardiovascular events are more likely after acute coronary syndrome (ACS) than in the setting of stable angina, and MetS is highly prevalent in ACS patients. ${ }^{4}$

Received December 22, 2011; revised manuscript received June 25, 2012; accepted July 24, 2012; released online September 7, 2012 Time for primary review: 31 days

Department of Cardiology, Aichi Medical University, Nagakute (H.T., T. Mizuno, K.A., Y. Kuroda, T. Kosaka, Y. Kuhara, A.K., K. Maeda, T.A.); Department of Cardiology, Fujita Health University, Toyoake (Y.O.); Center for General Internal Medicine and Emergency Care, Kinki University School of Medicine, Osaka-sayama (T. Morimoto); Division of Cardiology, Department of Cardiovascular Medicine, Kyoto University Graduate School of Medicine, Kyoto (T. Kimura); Division of Cardiology, Department of Medicine, Nihon University School of Medicine, Tokyo (T.H.); Department of Cardiology, Juntendo University School of Medicine, Tokyo (K. Miyauchi, H.D.); Department of Cardiology, Tenri Hospital, Tenri (Y.N.); Division of Cardiovascular Medicine, Kanazawa University Graduate School of Medicine, Kanazawa (M.Y.); and Division of Cardiology, Department of Medicine and Clinical Science, Yamaguchi University Graduate School of Medicine, Ube (M.M.), Japan

Trial Registration: ClinicalTrials.gov Identifier: NCT002429 [http://clinicaltrials.gov/ct2/show/NCT00242944].

Mailing address: Hiroaki Takashima, MD, PhD, Department of Cardiology, Aichi Medical University, Nagakute 480-1195, Japan. E-mail: h0914@aichi-med-u.ac.jp

ISSN-1346-9843 doi:10.1253/circj.CJ-11-1495

All rights are reserved to the Japanese Circulation Society. For permissions, please e-mail: cj@j-circ.or.jp 


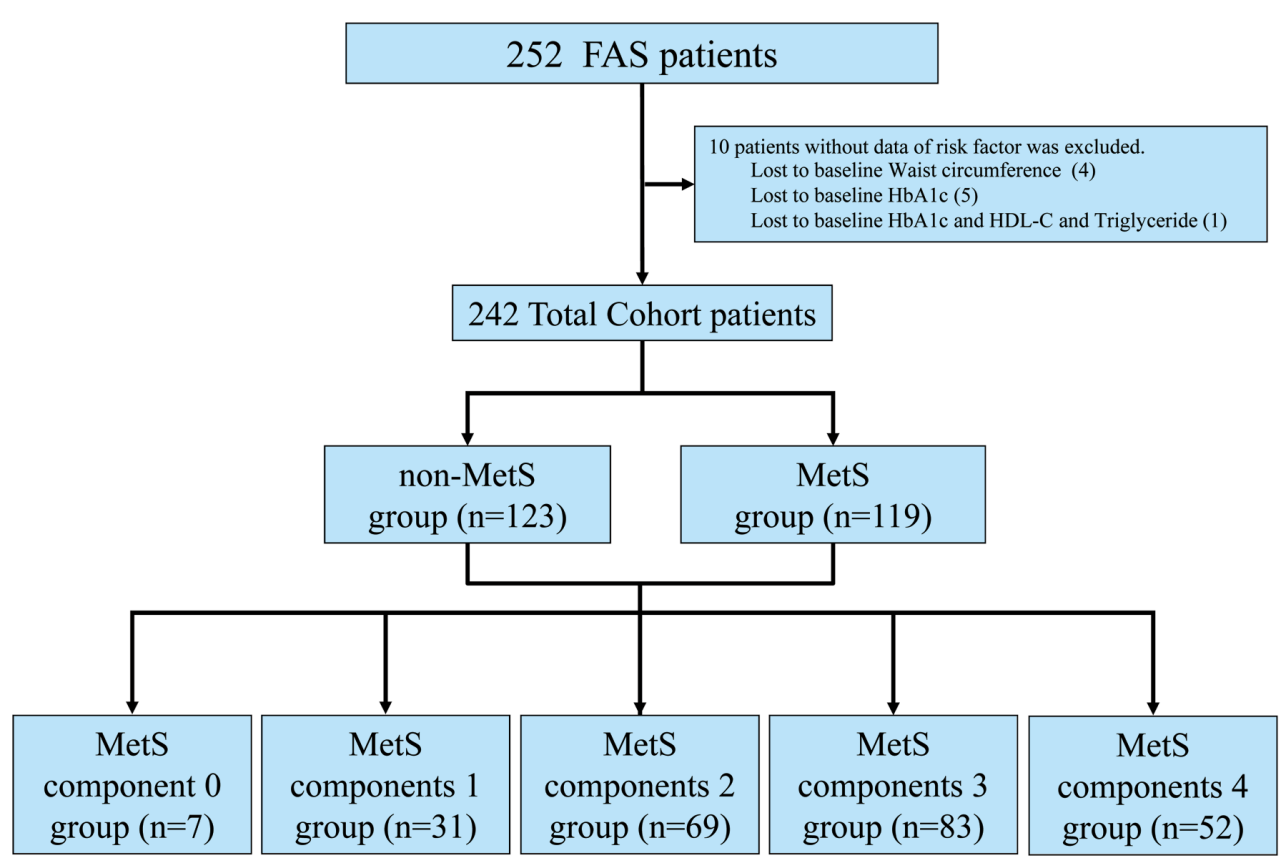

Figure 1. Disposition of the study patients.

\section{Editorial $p 2744$}

Furthermore, there is a higher incidence of adverse cardiovascular events in ACS patients with MetS than in those without MetS. ${ }^{5,6}$ Clinical trials have reported that HMG-CoA reductase inhibitors (statins) reduce the incidence of secondary cardiovascular events in patients with ACS. ${ }^{7,8}$ Moreover, an intravascular ultrasound (IVUS) study demonstrated that intensive statin therapy showed significant coronary plaque regression in patients with ACS. ${ }^{9}$ Accordingly, the JAPANACS (Japan Assessment of Pitavastatin and Atorvastatin in Acute Coronary Syndrome), a prospective, randomized, openlabel, parallel group study, was undertaken and demonstrated that intensive statin therapy with $4 \mathrm{mg} /$ day of pitavastatin or $20 \mathrm{mg} /$ day of atorvastatin in ACS patients resulted in significant regression of atheroma burden with negative vessel remodeling in a multicenter trial using a central IVUS core-laboratory. In addition, non-inferiority of pitavastatin to atorvastatin was demonstrated. ${ }^{10}$

A previous IVUS study showed that the degree of plaque regression was attenuated with individual component risk factors of MetS, rather than with the presence of MetS itself. ${ }^{11}$ However, it has not yet been clarified whether the prevalence of MetS and clustering of its components affects the degree of coronary plaque regression during intensive statin therapy in ACS patients. Therefore, the aim of the present study was to evaluate the impact of MetS and clustering of its components on the degree of coronary plaque regression during intensive statin therapy in Japanese ACS patients assessed by serial volumetric IVUS measurements.

\section{Methods}

\section{Study Design and Ethical Considerations}

We performed a subanalysis of the JAPAN-ACS study because the plaque regression effect of the 2 statins was shown to be equivalent in that study. ${ }^{10}$ The research protocol of JAPAN-ACS has been previously outlined in detail. ${ }^{12}$ Briefly, ACS patients were randomized within $72 \mathrm{~h}$ of successful PCI under IVUS guidance to receive either pitavastatin $(4 \mathrm{mg})$ or atorvastatin $(20 \mathrm{mg})$ daily. IVUS examination and blood sampling were performed at baseline and repeated after 8-12 months of the baseline PCI. The study was conducted in accordance with the principles of the Helsinki Declaration and approved by the institutional review boards of all 33 participating institutions. Written informed consent was given by each patient.

\section{Definitions of MetS and MetS Components}

MetS was defined according to the criteria of the Japanese Examination Committee. ${ }^{13}$ Waist circumference $\geq 85 \mathrm{~cm}$ in men or $\geq 90 \mathrm{~cm}$ in women, and 2 or more of the following criteria were considered to indicate MetS: (1) HDL-C $<40 \mathrm{mg} / \mathrm{dl}$ and/ or triglycerides $\geq 150 \mathrm{mg} / \mathrm{dl}$, (2) known hypertension or blood pressure $\geq 130 / 85 \mathrm{mmHg}$, (3) known diabetes mellitus or hemoglobin $\mathrm{A}_{1 \mathrm{c}}\left(\mathrm{HbA}_{1 \mathrm{c}}\right) \geq 5.8 \%$ (instead of fasting glucose level $\geq 110 \mathrm{mg} / \mathrm{dl}) .{ }^{14} \mathrm{HbA} 1 \mathrm{c}$ was represented as the National Glycohemoglobin Standardization Program (NGSP) value. Participants were divided into 5 groups according to the number of MetS components.

\section{IVUS Procedure and Examination}

Details of the IVUS procedure and examination are documented elsewhere. ${ }^{10}$ In brief, following IVUS-guided PCI for the culprit lesion in patients with ACS, a final IVUS examination for analysis was performed in the culprit vessel. An IVUS catheter Atlantis SR Pro2 (Boston Scientific, Natick, MA, USA) 


\begin{tabular}{|c|c|c|c|c|c|c|}
\hline No. of MetS components & $0(n=7)$ & $1(n=31)$ & $2(n=69)$ & $3(n=83)$ & $4(n=52)$ & $P$ value \\
\hline Age (years) & $60.1 \pm 11.3$ & $66.5 \pm 10.7$ & $63.3 \pm 11.9$ & $62.6 \pm 10.3$ & $59.7 \pm 11.3$ & 0.097 \\
\hline Male, n (\%) & $4(57)$ & $22(71)$ & $52(75)$ & $71(86)$ & $49(94)$ & 0.009 \\
\hline $\mathrm{BMI}\left(\mathrm{kg} / \mathrm{m}^{2}\right)$ & $21.8 \pm 1.2$ & $22.1 \pm 2.9$ & $22.9 \pm 3.1$ & $25.4 \pm 3.4$ & $25.8 \pm 3.1$ & $<0.0001$ \\
\hline Waist circumference (cm) & $77.1 \pm 5.3$ & $78.9 \pm 7.4$ & $83.4 \pm 8.5$ & $90.6 \pm 7.5$ & $92.2 \pm 6.2$ & $<0.0001$ \\
\hline History of MI, n (\%) & $0(0)$ & $0(0)$ & $4(6)$ & $5(6)$ & $5(10)$ & 0.442 \\
\hline History of angina, n (\%) & $0(0)$ & $3(10)$ & $6(9)$ & $5(6)$ & $6(12)$ & 0.733 \\
\hline Previous PCl, n (\%) & $0(0)$ & $0(0)$ & $4(6)$ & $8(10)$ & $5(10)$ & 0.351 \\
\hline Previous CABG, n (\%) & $0(0)$ & $0(0)$ & $1(1)$ & $0(0)$ & $0(0)$ & 0.642 \\
\hline Hypertension, n (\%) & $0(0)$ & $11(35)$ & $41(59)$ & $57(69)$ & $40(77)$ & $<0.0001$ \\
\hline Diabetes mellitus, n (\%) & $0(0)$ & $3(10)$ & $13(19)$ & $28(34)$ & $26(50)$ & $<0.0001$ \\
\hline Smoking, n (\%) & $0(0)$ & $15(48)$ & $26(38)$ & $43(52)$ & $31(60)$ & 0.013 \\
\hline \multicolumn{7}{|l|}{ Type of ACS } \\
\hline AMI, n (\%) & $6(86)$ & $21(68)$ & $59(86)$ & $67(81)$ & $37(71)$ & 0.181 \\
\hline UAP, n (\%) & $1(14)$ & $10(32)$ & $10(14)$ & $16(19)$ & $15(29)$ & 0.181 \\
\hline Abnormal Q-wave, n (\%) & $1(14)$ & $10(32)$ & $21(30)$ & $32(39)$ & $17(33)$ & 0.655 \\
\hline Max CK median (IQR) (IU/L) & $\begin{array}{c}1,764 \\
(652-1,887)\end{array}$ & $\begin{array}{c}438 \\
(126-1,983)\end{array}$ & $\begin{array}{c}1,798 \\
(327-3,205)\end{array}$ & $\begin{array}{c}1,382 \\
(393-2,406)\end{array}$ & $\begin{array}{c}518 \\
(194-1,890)\end{array}$ & 0.374 \\
\hline Culprit vessel & & & & & & 0.200 \\
\hline $\mathrm{RCA}, \mathrm{n}(\%)$ & $4(57)$ & $7(23)$ & $18(26)$ & $34(41)$ & $15(29)$ & \\
\hline LAD, n (\%) & $2(29)$ & $23(74)$ & $40(58)$ & $37(45)$ & $29(56)$ & \\
\hline LCX, n (\%) & $1(14)$ & $1(3)$ & $11(16)$ & $11(13)$ & $8(15)$ & \\
\hline LMT, n (\%) & $0(0)$ & $0(0)$ & $0(0)$ & $1(1)$ & $0(0)$ & \\
\hline \multicolumn{7}{|l|}{ IVUS analysis segment } \\
\hline Proximal to the culprit, $\mathrm{n}(\%)$ & $0(0)$ & $9(29)$ & $24(35)$ & $26(31)$ & $15(29)$ & 0.435 \\
\hline Distal to the culprit, $\mathrm{n}(\%)$ & $7(100)$ & $22(71)$ & $45(65)$ & $57(69)$ & $37(71)$ & 0.435 \\
\hline \multicolumn{7}{|l|}{ Concomitant drugs } \\
\hline \multicolumn{7}{|l|}{ Statins } \\
\hline Pitavastatin, n (\%) & $4(57)$ & $15(48)$ & $41(59)$ & $37(45)$ & $24(46)$ & 0.419 \\
\hline Atorvastatin, n (\%) & $3(43)$ & $16(52)$ & $28(41)$ & $46(55)$ & $28(54)$ & 0.419 \\
\hline Aspirin, $\mathrm{n}(\%)$ & $7(100)$ & $31(100)$ & $68(99)$ & $81(98)$ & $51(98)$ & 0.914 \\
\hline Ticlopidine, n (\%) & $6(86)$ & $24(77)$ & $58(84)$ & $67(81)$ & $46(88)$ & 0.702 \\
\hline Clopidogrel, n (\%) & $0(0)$ & $2(6)$ & $5(7)$ & $6(7)$ & $3(6)$ & 0.957 \\
\hline ARB, n (\%) & $2(29)$ & $16(52)$ & $28(41)$ & $44(53)$ & $29(56)$ & 0.320 \\
\hline ACEI, n (\%) & $3(43)$ & $5(16)$ & $26(38)$ & $27(33)$ & $11(21)$ & 0.110 \\
\hline CCB, n (\%) & $0(0)$ & $7(23)$ & $10(14)$ & $17(20)$ & $14(27)$ & 0.310 \\
\hline Nitrate, n (\%) & $1(14)$ & $5(16)$ & $15(22)$ & $13(16)$ & $4(8)$ & 0.350 \\
\hline$\beta$-blocker, n (\%) & $2(29)$ & $15(48)$ & $30(43)$ & $37(45)$ & $25(48)$ & 0.882 \\
\hline
\end{tabular}

Data are expressed as $\mathrm{n}(\%)$ unless otherwise specified. Continuous variables were represented by mean $\pm \mathrm{SD}$ or median (IQR).

$\mathrm{ACE}$, angiotensin-converting enzyme inhibitor; ACS, acute coronary syndrome; AMI, acute coronary infarction; ARB, angiotensin receptor blocker; BMI, body mass index; CABG, coronary artery bypass grafting; CCB, calcium-channel blocker; IQR, intraquartile range; LAD, left anterior descending; LCX, left circumflex branch; LMT, left main trunk; MI, myocardial infarction; PCl, percutaneous coronary intervention; $\mathrm{RCA}$, right coronary artery; UAP, unstable angina pectoris.

was used, and a motorized pullback device withdrew the transducer at the speed of $0.5 \mathrm{~mm} / \mathrm{s}$. The consoles used were the ClearView or Galaxy 2 system (Boston Scientific). The same imaging system with the same type of IVUS catheter was used for both the baseline and follow-up examinations. Two independent experienced investigators performed the quantitative IVUS analysis at a central core-laboratory. The target segment for analysis was identified at a non-PCI site of the culprit vessel ( $>5 \mathrm{~mm}$ proximal or distal to the PCI site) based on some reproducible indices. Manual tracing was performed in every 0.1-mm cross-section and the software (echoPlaque2, INDEC systems, Santa Clara, CA, USA) automatically interpolated the tracings of 5 cross-sections between 2 manually traced images. Therefore, the volume was calculated from each of the $0.017-\mathrm{mm}$ separated segments.

\section{IVUS Measurements}

Coronary plaque volume (PV) was calculated as the sum of the differences between the external elastic membrane (EEM) and lumen area across all evaluated frames as:

$$
\mathrm{PV}=\sum(\text { EEMCSA-LUMENCSA }) \text {, }
$$

where CSA is the cross-sectional area. The percent change in PV after 8-12 months of pitavastatin or atorvastatin therapy was calculated as:

$$
\frac{\mathrm{PV}(\text { follow up })-\mathrm{PV}(\text { baseline })}{\mathrm{PV}(\text { baseline })} \times 100
$$

\section{Statistical Analysis}

We evaluated a complete full analysis set (FAS) of the JAPAN- 


\begin{tabular}{|c|c|c|c|c|c|c|}
\hline \multicolumn{6}{|l|}{ Systolic BP (mmHg) } & $P$ value \\
\hline Baseline & $114.4 \pm 12.8$ & $127.6 \pm 24.4$ & $137.5 \pm 21.9$ & $138.8 \pm 26.7$ & $147.6 \pm 25.8$ & 0.001 \\
\hline Follow-up & $124.9 \pm 15.5$ & $125.5 \pm 15.6$ & $127.3 \pm 18.8$ & $130.4 \pm 16.3$ & $128.5 \pm 17.2$ & 0.620 \\
\hline \multicolumn{7}{|l|}{ Diastolic BP (mmHg) } \\
\hline Baseline & $69.6 \pm 10.4$ & $74.5 \pm 15.7$ & $79.4 \pm 14.4$ & $77.9 \pm 14.9$ & $82.3 \pm 16.9$ & 0.091 \\
\hline Follow-up & $66.7 \pm 21.2$ & $72.1 \pm 9.9$ & $70.3 \pm 12.0$ & $75.3 \pm 12.1$ & $74.3 \pm 13.3$ & 0.073 \\
\hline \multicolumn{7}{|l|}{ Total cholesterol (mg/dl) } \\
\hline Baseline & $210.1 \pm 48.7$ & $200.4 \pm 37.4$ & $192.6 \pm 32.9$ & $198.3 \pm 35.6$ & $195.0 \pm 37.8$ & 0.649 \\
\hline Follow-up & $165.6 \pm 41.4$ & $152.8 \pm 25.4$ & $155.5 \pm 29.2$ & $148.2 \pm 32.8$ & $150.6 \pm 28.4$ & 0.443 \\
\hline Percent change & $-19.1 \pm 20.1$ & $-22.3 \pm 14.9$ & $-18.0 \pm 16.3$ & $-24.5 \pm 15.7$ & $-20.6 \pm 19.3$ & 0.196 \\
\hline \multicolumn{7}{|l|}{ LDL-C (mg/dl) } \\
\hline Baseline & $132.4 \pm 40.6$ & $138.1 \pm 38.1$ & $128.3 \pm 29.2$ & $132.6 \pm 31.0$ & $131.9 \pm 32.6$ & 0.723 \\
\hline Follow-up & $89.0 \pm 34.5$ & $82.4 \pm 20.9$ & $85.2 \pm 25.8$ & $78.5 \pm 24.9$ & $85.1 \pm 24.0$ & 0.408 \\
\hline Percent change & $-28.8 \pm 28.7$ & $-38.4 \pm 15.3$ & $-32.0 \pm 21.2$ & $-39.6 \pm 20.0$ & $-32.5 \pm 24.2$ & 0.123 \\
\hline \multicolumn{7}{|l|}{ Triglycerides (mg/dl) } \\
\hline Baseline & $83.1 \pm 34.9$ & $83.5 \pm 28.1$ & $102.9 \pm 42.4$ & $128.2 \pm 59.0$ & $147.4 \pm 61.1$ & $<0.0001$ \\
\hline Follow-up & $65.3 \pm 18.6$ & $99.9 \pm 43.9$ & $120.6 \pm 80.6$ & $133.8 \pm 77.2$ & $138.5 \pm 58.5$ & 0.016 \\
\hline Percent change & $-12.2 \pm 33.2$ & $28.9 \pm 59.7$ & $33.4 \pm 89.5$ & $16.0 \pm 61.1$ & $2.8 \pm 48.2$ & 0.083 \\
\hline \multicolumn{7}{|l|}{ HDL-C (mg/dl) } \\
\hline Baseline & $61.0 \pm 14.3$ & $48.4 \pm 7.5$ & $45.7 \pm 8.6$ & $43.8 \pm 9.3$ & $37.9 \pm 7.5$ & $<0.0001$ \\
\hline Follow-up & $62.9 \pm 12.1$ & $52.9 \pm 11.0$ & $48.5 \pm 9.8$ & $46.7 \pm 13.8$ & $42.5 \pm 10.3$ & $<0.0001$ \\
\hline Percent change & $5.8 \pm 23.6$ & $10.5 \pm 22.5$ & $7.4 \pm 19.2$ & $7.2 \pm 24.8$ & $13.4 \pm 23.3$ & 0.552 \\
\hline \multicolumn{7}{|l|}{ LDL-C/HDL-C } \\
\hline Baseline & $2.3 \pm 0.8$ & $2.9 \pm 1.0$ & $2.9 \pm 0.7$ & $3.1 \pm 0.9$ & $3.6 \pm 0.9$ & $<0.0001$ \\
\hline Follow-up & $1.4 \pm 0.5$ & $1.6 \pm 0.5$ & $1.8 \pm 0.7$ & $1.8 \pm 0.7$ & $2.1 \pm 0.7$ & 0.007 \\
\hline Percent change & $-30.3 \pm 31.1$ & $-43.1 \pm 13.6$ & $-35.3 \pm 21.9$ & $-41.7 \pm 21.5$ & $-39.1 \pm 21.8$ & 0.223 \\
\hline \multicolumn{7}{|l|}{ RLP-C (mg/dl) } \\
\hline Baseline & $4.0 \pm 1.6$ & $3.6 \pm 0.9$ & $4.0 \pm 2.0$ & $4.4 \pm 3.0$ & $5.2 \pm 3.1$ & 0.038 \\
\hline Follow-up & $2.3 \pm 1.1$ & $2.9 \pm 1.7$ & $4.1 \pm 4.1$ & $4.3 \pm 3.2$ & $4.1 \pm 2.3$ & 0.157 \\
\hline Percent change & $-36.5 \pm 28.8$ & $-19.1 \pm 45.1$ & $18.3 \pm 100.3$ & $20.2 \pm 97.2$ & $-12.5 \pm 51.1$ & 0.029 \\
\hline \multicolumn{7}{|l|}{ MDA-LDL (U/L) } \\
\hline Baseline & $102.4 \pm 35.9$ & $111.9 \pm 29.6$ & $128.1 \pm 43.7$ & $133.5 \pm 44.2$ & $140.0 \pm 58.7$ & 0.037 \\
\hline Follow-up & $89.1 \pm 26.4$ & $81.8 \pm 22.1$ & $93.0 \pm 29.3$ & $91.8 \pm 33.0$ & $95.0 \pm 35.5$ & 0.425 \\
\hline Percent change & $-6.1 \pm 35.5$ & $-23.1 \pm 26.1$ & $-22.4 \pm 28.5$ & $-28.1 \pm 24.7$ & $-26.2 \pm 27.1$ & 0.251 \\
\hline \multicolumn{7}{|c|}{ hs-CRP median (IQR) (mg/L) } \\
\hline Baseline & $\begin{array}{c}7.9 \\
(5.3-19.9)\end{array}$ & $\begin{array}{c}16.0 \\
(4.1-65.2)\end{array}$ & $\begin{array}{c}24.2 \\
(4.8-67.8)\end{array}$ & $\begin{array}{c}14.9 \\
(4.7-50.1)\end{array}$ & $\begin{array}{c}25.2 \\
(6.1-74.7)\end{array}$ & 0.135 \\
\hline Follow-up & $\begin{array}{c}0.4 \\
(0.1-0.5)\end{array}$ & $\begin{array}{c}0.4 \\
(0.2-0.5)\end{array}$ & $\begin{array}{c}0.5 \\
(0.3-0.8)\end{array}$ & $\begin{array}{c}0.5 \\
(0.3-1.2)\end{array}$ & $\begin{array}{c}0.8 \\
(0.5-1.7)\end{array}$ & 0.546 \\
\hline Percent change & $\begin{array}{c}-98.3 \\
(-98.9 \text { to }-93.0)\end{array}$ & $\begin{array}{c}-97.1 \\
(-99.4 \text { to }-93.9)\end{array}$ & $\begin{array}{c}-97.5 \\
(-99.3 \text { to }-87.9)\end{array}$ & $\begin{array}{c}-95.3 \\
(-98.4 \text { to }-89.2)\end{array}$ & $\begin{array}{c}-97.2 \\
(-98.8 \text { to }-88.1)\end{array}$ & 0.513 \\
\hline \multicolumn{7}{|l|}{$\mathrm{HbA}_{1 \mathrm{c}}(\%)$} \\
\hline Baseline & $5.5 \pm 0.1$ & $5.7 \pm 0.7$ & $6.1 \pm 1.2$ & $6.4 \pm 1.1$ & $6.9 \pm 1.3$ & $<0.0001$ \\
\hline Follow-up & $5.7 \pm 0.2$ & $5.8 \pm 0.3$ & $6.2 \pm 1.0$ & $6.4 \pm 0.9$ & $6.8 \pm 1.3$ & $<0.0001$ \\
\hline Percent change & $0.2 \pm 0.2$ & $0.1 \pm 0.6$ & $0.1 \pm 0.6$ & $0.0 \pm 0.8$ & $-0.1 \pm 1.1$ & 0.588 \\
\hline
\end{tabular}

Values are mean \pm SD or median (IQR).

ACS, acute coronary syndrome; $\mathrm{HbA}_{1 c}$, hemoglobin $\mathrm{A}_{1 \mathrm{c}}$; HDL-C, high-density lipoprotein cholesterol; hs-CRP, high-sensitivity C-reactive protein; LDL-C, low-density lipoprotein cholesterol; MDA-LDL, malondialdehyde-modified low-density lipoprotein; RLP-C, remnant-like particle-cholesterol.

$\mathrm{HbA} A_{1 c}$ levels are represented as National Glycohemoglobin Standardization Program (NGSP) values.

ACS study for this subanalysis. Patients were included in the FAS if they had ACS and measurable IVUS lesions at both enrollment and follow-up. Descriptive statistics are presented as mean $\pm \mathrm{SD}$ or $\mathrm{n}(\%)$. Differences between groups were assessed with the chi-square test for categorical variables, and assessed with ANOVA or Wilcoxon rank-sum test for continuous variables. Differences between baseline and follow-up were assessed with paired t-test or Wilcoxon signed rank test. We conducted a trend test for the relationship between the number of MetS components and the percent change in PV. The correlation between the percent change in PV and the percent change in body mass index (BMI) were analyzed by linear regression analysis and correlation coefficient. All statistical analyses were performed with JMP8 (SAS Institute, 

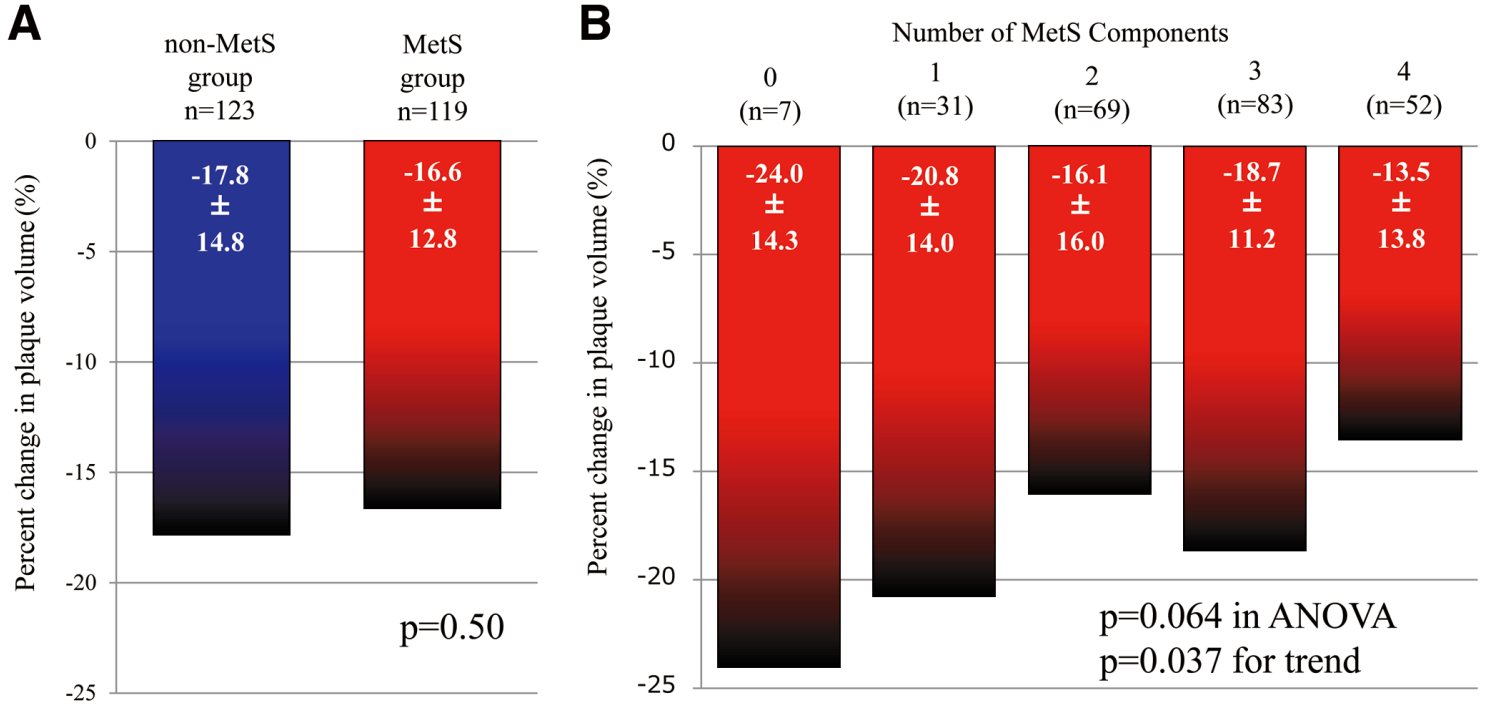

Figure 2. Components of the metabolic syndrome (MetS) and the degree of plaque regression. (A) Percent change in plaque volume in the non-MetS and MetS groups. (B) Percent change in plaque volume in the 5 groups according to MetS components. Variables are represented by mean \pm SD.

Cary, NC, USA). A value of $\mathrm{P}<0.05$ was considered statistically significant.

\section{Results}

\section{Baseline Characteristics}

The disposition of the patients in the present study is shown in Figure 1; 10 patients lacking data on their risk factors were excluded from the analyses of the total of 252 FAS patients. The remaining 242 patients were divided into MetS $(n=119)$ and non-MetS $(n=123)$ groups, and further divided into 5 groups according to the number of components: MetS components 0 $(n=7)$, MetS components $1(n=31)$, MetS components $2(n=69)$, MetS components $3(n=83)$, and MetS components $4(n=52)$. Most of the baseline clinical characteristics were comparable among the 5 groups (Table 1). Some parameters such as sex $(\mathrm{P}=0.009), \mathrm{BMI}(\mathrm{P}<0.0001)$, waist circumference $(\mathrm{P}<0.0001)$, hypertension $(\mathrm{P}<0.0001)$, diabetes mellitus $(\mathrm{P}<0.0001)$, and smoking habit $(\mathrm{P}=0.013)$ were significantly different among the 5 groups.

\section{Baseline and Follow-up Laboratory Data}

The laboratory data at baseline and follow-up are shown in Table 2. At baseline, there was no significant difference in low-density lipoprotein cholesterol (LDL-C) level among the 5 groups $(\mathrm{P}=0.723)$, whereas systolic blood pressure $(\mathrm{SBP})$ $(\mathrm{P}=0.001)$, triglycerides $(\mathrm{P}<0.0001)$, HDL-C level $(\mathrm{P}<0.0001)$, LDL-C/HDL-C ratio $(\mathrm{P}<0.0001)$, remnant-like particle-cholesterol (RLP-C) level $(\mathrm{P}=0.038)$, malondialdehyde-modified (MDA)-LDL level $(\mathrm{P}=0.037)$ and $\mathrm{HbA}_{1 c}(\mathrm{P}<0.0001)$ were significantly different among the 5 groups.

During the treatment period, the LDL-C level was similar among the 5 groups $(\mathrm{P}=0.408)$.

\section{Plaque Regression in the MetS and Non-MetS Groups}

Although there was a significant reduction of PV in both the MetS and non-MetS groups $(\mathrm{P}<0.0001$ and $\mathrm{P}<0.0001$, respec- tively), the degree of the percent change in PV was not different between the groups at follow-up $(-16.6 \pm 12.8 \%$ vs. $-17.8 \pm 14.8 \%, \mathrm{P}=0.50$ ) (Figure 2A).

\section{IVUS Parameters and the Number of MetS Components}

The IVUS parameters among the 5 MetS component groups were assessed and although there was no significant difference in IVUS parameters among the 5 groups, the degree of plaque regression was significantly attenuated with an increasing number of MetS components (MetS components 0: $-24.0 \pm 14.3 \%$; MetS components 1: $-20.8 \pm 14.0 \%$; MetS components $2:-16.1 \pm 16.0 \%$; MetS components $3:-18.7 \pm 11.2 \%$; MetS components 4: $-13.5 \pm 13.8 \%, \mathrm{P}=0.037$ for trend) (Table 3, Figure 2B).

\section{Correlation Between BMI and PV}

The correlation between BMI and PV was assessed (Figure 3). The percent change in BMI significantly correlated with the percent change in $\mathrm{PV}(\mathrm{r}=0.15, \mathrm{P}=0.021)$, especially in the MetS components 4 group $(\mathrm{r}=0.35, \mathrm{P}=0.017)$. In addition, the percent change in $\mathrm{BMI}$ was an independent predictor of $\mathrm{PV}$ change $(\beta=0.289,95 \%$ confidence interval (CI) $0.05-0.53$ per increment of $1 \%$ ) after adjusted for change of LDL-C, triglycerides, HDL-C, and HbAic (Table 4).

\section{Major Adverse Cardiovascular Events (MACE)}

In the 1-year clinical follow-up, there was a significant difference in the prevalence of MACE (the incidence of coronary revascularization, and myocardial infarction) among the 5 MetS components groups ( $0 \%$ vs. $9.7 \%$ vs. $15.9 \%$ vs. $30.1 \%$ vs. $25.0 \%, \mathrm{P}=0.044)$.

\section{Discussion}

In the JAPAN-ACS study, marked plaque regression in ACS patients was associated with intensive lipid-lowering therapy by statins. ${ }^{10}$ However, little is known about whether the pres- 
A

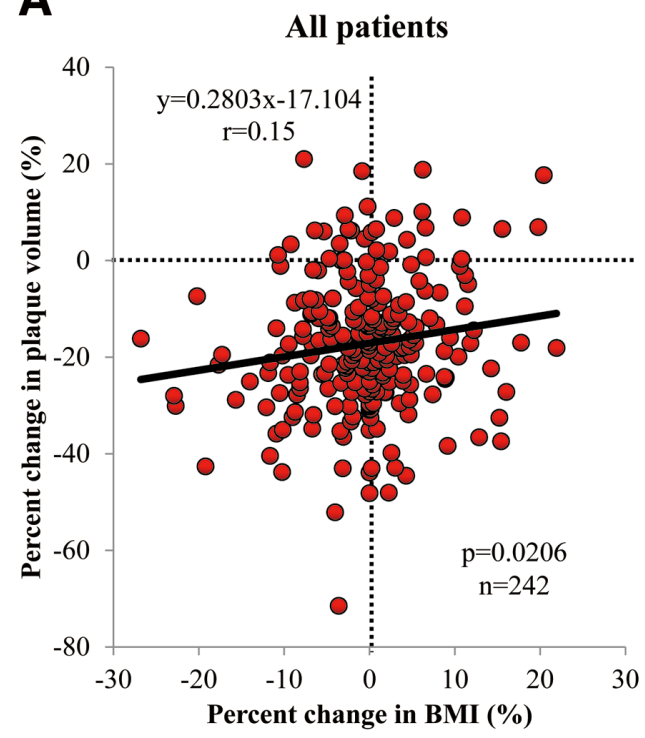

B

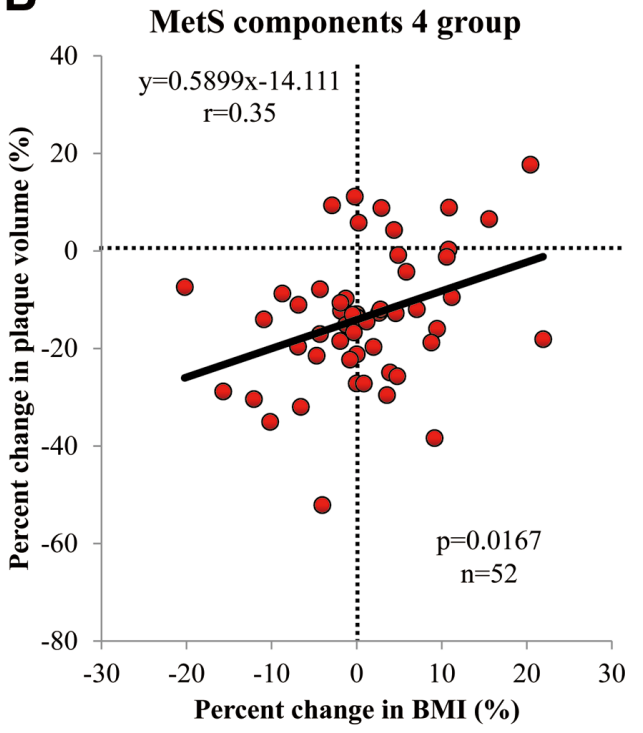

Figure 3. Correlation between percent change in body mass index (BMI) and percent change in plaque volume. Relationship between percent change in $\mathrm{BMI}$ and percent change in plaque volume in all patients $(\mathbf{A})$ and the metabolic syndrome (MetS) components 4 group (B).

\begin{tabular}{|c|c|c|c|c|c|c|}
\hline No. of MetS components & $0(n=7)$ & $1(n=31)$ & $2(n=69)$ & $3(n=83)$ & $4(n=52)$ & $P$ value \\
\hline Analyzed length at baseline (mm) & $7.4 \pm 1.5$ & $6.6 \pm 3.0$ & $6.4 \pm 3.4$ & $6.9 \pm 2.9$ & $6.8 \pm 2.9$ & 0.782 \\
\hline \multicolumn{7}{|l|}{ Plaque volume $\left(\mathrm{mm}^{3}\right)$} \\
\hline Baseline & $60.0 \pm 22.4$ & $58.7 \pm 32.1$ & $52.1 \pm 34.3$ & $58.2 \pm 31.4$ & $58.7 \pm 32.8$ & 0.741 \\
\hline Follow-up & $46.5 \pm 20.9$ & $46.1 \pm 26.7$ & $45.7 \pm 35.2$ & $47.5 \pm 26.4$ & $50.9 \pm 28.3$ & 0.904 \\
\hline Percent change & $-24.0 \pm 14.3$ & $-20.8 \pm 14.0$ & $-16.1 \pm 16.0$ & $-18.7 \pm 11.2$ & $-13.5 \pm 13.8$ & 0.064 \\
\hline \multicolumn{7}{|l|}{ Vessel volume $\left(\mathrm{mm}^{3}\right)$} \\
\hline Baseline & $116.0 \pm 28.7$ & $115.4 \pm 57.4$ & $105.6 \pm 64.0$ & $114.4 \pm 56.1$ & $117.2 \pm 63.9$ & 0.842 \\
\hline Follow-up & $104.7 \pm 24.6$ & $103.8 \pm 49.8$ & $100.9 \pm 63.4$ & $106.3 \pm 50.2$ & $111.1 \pm 58.0$ & 0.904 \\
\hline Percent change & $-9.0 \pm 8.2$ & $-8.3 \pm 11.3$ & $-4.8 \pm 12.7$ & $-5.9 \pm 10.8$ & $-4.7 \pm 10.5$ & 0.549 \\
\hline \multicolumn{7}{|l|}{ Lumen volume $\left(\mathrm{mm}^{3}\right)$} \\
\hline Baseline & $56.0 \pm 9.6$ & $56.7 \pm 30.7$ & $53.6 \pm 33.2$ & $56.2 \pm 29.5$ & $58.5 \pm 35.7$ & 0.947 \\
\hline Follow-up & $58.2 \pm 7.6$ & $57.7 \pm 29.3$ & $55.2 \pm 32.8$ & $58.8 \pm 27.8$ & $60.1 \pm 34.3$ & 0.927 \\
\hline Percent change & $4.9 \pm 8.4$ & $5.7 \pm 19.9$ & $7.1 \pm 21.8$ & $8.3 \pm 20.8$ & $5.5 \pm 20.4$ & 0.935 \\
\hline \multicolumn{7}{|l|}{ Plaque volume (\%) } \\
\hline Baseline & $50.2 \pm 8.9$ & $50.1 \pm 10.2$ & $48.7 \pm 11.2$ & $50.2 \pm 10.6$ & $50.8 \pm 9.4$ & 0.855 \\
\hline Follow-up & $42.3 \pm 11.5$ & $43.2 \pm 10.6$ & $43.1 \pm 11.9$ & $43.6 \pm 10.6$ & $46.2 \pm 10.3$ & 0.555 \\
\hline Nominal change & $-7.9 \pm 4.5$ & $-7.0 \pm 6.7$ & $-5.6 \pm 6.6$ & $-6.7 \pm 5.6$ & $-4.6 \pm 6.5$ & 0.268 \\
\hline \multicolumn{7}{|l|}{ Normalized plaque volume $\left(\mathrm{mm}^{3}\right)$} \\
\hline Baseline & $50.5 \pm 12.4$ & $55.3 \pm 15.9$ & $52.8 \pm 19.8$ & $54.5 \pm 19.9$ & $56.0 \pm 19.0$ & 0.875 \\
\hline Follow-up & $38.8 \pm 13.3$ & $43.8 \pm 14.2$ & $45.0 \pm 20.5$ & $44.4 \pm 17.5$ & $48.5 \pm 18.1$ & 0.566 \\
\hline Nominal change & $-11.6 \pm 6.7$ & $-11.5 \pm 9.2$ & $-7.8 \pm 8.7$ & $-10.1 \pm 7.4$ & $-7.5 \pm 7.8$ & 0.080 \\
\hline
\end{tabular}

Values are mean \pm SD. ACS, acute coronary syndrome; IVUS, intravascular ultrasound.

ence of MetS or the number of MetS components affects coronary plaque progression/regression in patients with ACS.

In our subanalysis of the multicenter JAPAN-ACS study, we evaluated the degree of plaque regression between MetS and non-MetS subgroups and subgroups according to the number of MetS components in patients with ACS undergoing intensive lipid-lowering therapy.

There was no difference in the degree of plaque regression between the MetS and non-MetS groups, but the degree of plaque regression was significantly attenuated according to the number of MetS components (components 0-4), although the baseline and follow-up LDL-C levels were similar between 


\begin{tabular}{|c|c|c|c|c|c|c|}
\hline \multirow{2}{*}{ Factor } & \multicolumn{3}{|c|}{ All patients $(n=242)$} & \multicolumn{3}{|c|}{ MetS components 4 group $(n=52)$} \\
\hline & $\boldsymbol{\beta}$ & $95 \% \mathrm{Cl}$ & $P$ value & $\beta$ & $95 \% \mathrm{Cl}$ & $P$ value \\
\hline Percent change in BMI (\%) & 0.289 & 0.05 to 0.53 & 0.020 & 0.594 & 0.13 to 1.06 & 0.013 \\
\hline Percent change in LDL-C (\%) & 0.076 & -0.01 to 0.16 & 0.084 & -0.062 & -0.23 to 0.11 & 0.470 \\
\hline Percent change in triglycerides (\%) & -0.006 & -0.03 to 0.02 & 0.626 & 0.081 & 0.00 to 0.16 & 0.053 \\
\hline Percent change in HDL-C (\%) & -0.028 & -0.11 to 0.05 & 0.497 & 0.01 & -0.16 to 0.18 & 0.902 \\
\hline Percent change in $\mathrm{HbA}_{1 \mathrm{c}}(\%)$ & -2.007 & -4.28 to 0.27 & 0.083 & 0.056 & -3.48 to 3.59 & 0.975 \\
\hline
\end{tabular}

Abbreviations as in Tables 1,2.

groups. We previously reported that MetS was significantly associated with either large lipid volume or small fibrous volume among 122 PCI-treated patients with mild to moderate stable coronary lesions identified by integrated backscatter IVUS. In that study, there was a significant difference in the ratio of lipid-rich plaque among 3 of the MetS components groups: MetS components 0-2, MetS components 3, and MetS components $4-5 .{ }^{15}$ It was concluded that MetS was an independent predictor of lipid-rich plaque, contributing to an increased risk of cardiovascular disease. However, an observational study can not evaluate the impact of MetS and its components on coronary PV change in ACS patients under statin intervention. Considering both previous study ${ }^{15}$ and present study, the number of MetS components could be associated with coronary plaque quantity and quality.

To our knowledge, our analysis is the first investigation of whether the number of MetS components affects coronary plaque progression/regression in ACS patients.

The MetS consists of metabolic abnormalities, among which visceral obesity plays a central role. ${ }^{16} \mathrm{HDL}-\mathrm{C}$ has anti-atherosclerotic properties because it not only scavenges excess cholesterol from peripheral vessels but also has antiinflammatory and antioxidative effects. ${ }^{17,18}$ Previous reports documented that changes in coronary PV correlated inversely with the changes in plasma levels of HDL-C. ${ }^{19,20}$ These findings suggest that HDL-C plays an important role in coronary plaque progression/regression.

It has not been adequately investigated whether the triglyceride level correlates with coronary plaque progression/regression, although that level is known to correlate inversely with the HDL-C level. ${ }^{21}$

With regard to diabetes mellitus, Hiro et al reported that the regression of coronary plaque induced by statin therapy was weaker in diabetic patients $(-12.8 \%)$ than in non-diabetics patients $(-19.4 \%)$, even though the reduction in LDL-C levels was similar. ${ }^{22}$ These results suggest the abnormal glucose tolerance, which is a MetS component, might attenuate the effect of statins on coronary plaque regression.

Sipahi et al demonstrated a continuous relationship between SBP and the rate of progression of coronary atherosclerosis over a broad range of blood pressure from $100 \mathrm{mmHg}$ to the hypertensive range. ${ }^{23}$ A previous IVUS study ${ }^{9}$ evaluated coronary plaque progression/regression in ACS patients with lipidlowering therapy by statins, and it is now generally recognized that the degree of plaque regression correlates well with LDL$\mathrm{C}$ reduction. ${ }^{9,24,25}$ However, the concept of MetS does not include the component of LDL-C level, so we should recognize MetS components as a residual risk of coronary atherosclerosis even if the LDL-C level is well-controlled to guidelinerecommended levels.

The pathology of MetS mainly derives from obesity or visceral fat. Previous reports have assessed BMI as well as waist circumference as a MetS component and BMI is recognized as a risk factor for cardiovascular events.,26-28 Tani et al demonstrated that baseline BMI correlated with coronary PV change, and an increase in BMI attenuated pravastatin-induced coronary plaque regression in their IVUS study. ${ }^{29}$ In the present study, baseline BMI showed a positive correlation with baseline waist circumference ( $\mathrm{r}=0.75, \mathrm{P}<0.0001$, unpublished data), and the change in BMI during the study period significantly correlated with coronary PV change. In addition, the change in BMI was an independent predictor of coronary plaque progression even after adjustment for change in LDL-C, triglycerides, HDL-C and HbAic. From the perspective of prevention, a management of obesity, in addition to the effect of the clustering of MetS components at baseline, could induce more coronary plaque regression in ACS patients under intensive lipid-lowering therapy.

\section{Study Limitations}

First, this study was a relatively small IVUS study of 242 participants. However, the JAPAN-ACS study was one of the largest serial IVUS studies conducted in the setting of ACS. ${ }^{10}$ Second, it remains to be determined whether coronary plaque regression translates into improved clinical outcomes. However, there are several studies that have shown that coronary plaque progression or regression observed by IVUS serves as a predictor of future cardiovascular events..$^{30-32}$

\section{Conclusions}

Coronary plaque regression induced under intensive statin therapy after PCI for ACS was attenuated according to the clustering of MetS components. In addition, an improvement in obesity is an independent predictor of coronary plaque regression in these patients. Therefore, to achieve a greater degree of plaque regression in ACS patients, it is necessary to treat to each MetS component and the obesity, which are located upstream of the MetS pathogenesis, in addition to intensive statin therapy.

\section{Sources of Funding}

The Japan Heart Foundation funded this study with an unrestricted grant from Kowa Pharmaceutical. Kowa Pharmaceutical participated in the study design. However, investigators or independent Clinical Research Coordinators conducted database maintenance, created the manuscript, and decided to submit the article, and an independent statistician analyzed the data.

\section{Disclosures}

Drs Takashima, Mizuno, Asai, Kuroda, Kosaka, Kuhara, Kurita, Maeda and Amano have no conflicts of interest. Dr Ozaki has received honoraria for lectures and research grants from Pfizer and Kowa Pharmaceutical. Dr Morimoto has received honoraria for lectures from Kowa Pharmaceutical and Pfizer. Dr Kimura has received honoraria for lectures from Kowa 
Pharmaceutical, Pfizer and Astellas Pharma. Drs Hiro, Miyauchi, Nakagawa, and Yamagishi have received honoraria for lectures from Kowa Pharmaceutical, Pfizer and Astellas Pharma. Drs Daida and Matsuzaki have received honoraria for lectures and research grants from Kowa Pharmaceutical, Pfizer and Astellas Pharma.

\section{References}

1. Malik S, Wong ND, Franklin SS, Kamath TV, L'Italien GJ, Pio JR, et al. Impact of the metabolic syndrome on mortality from coronary heart disease, cardiovascular disease, and all causes in United States adults. Circulation 2004; 110: $1245-1250$

2. Takeuchi H, Saitoh S, Takagi S, Ohnishi H, Ohhata J, Isobe T, et al. Metabolic syndrome and cardiac disease in Japanese men: Applicability of the concept of metabolic syndrome defined by the National Cholesterol Education Program-Adult Treatment Panel III to Japanese men: The Tanno and Sobetsu Study. Hypertens Res 2005; 28: 203 208.

3. Gami AS, Witt BJ, Howard DE, Erwin PJ, Gami LA, Somers VK, et al. Metabolic syndrome and risk of incident cardiovascular events and death: A systematic review and meta-analysis of longitudinal studies. J Am Coll Cardiol 2007; 49: 403-414.

4. Nakatani D, Sakata Y, Sato H, Mizuno H, Shimizu M, Suna S, et al. Clinical impact of metabolic syndrome and its additive effect with smoking on subsequent cardiac events after acute myocardial infarction. Am J Cardiol 2007; 99: 885-889.

5. Dohi T, Miyauchi K, Kasai T, Kajimoto K, Kubota N, Tamura H, et al. Impact of metabolic syndrome on 10-year clinical outcomes among patients with acute coronary syndrome. Circ J 2009; 73: 1454-1458.

6. Feinberg MS, Schwartz R, Tanne D, Fisman EZ, Hod H, Zahger D, et al. Impact of the metabolic syndrome on the clinical outcomes of non-clinically diagnosed diabetic patients with acute coronary syndrome. Am J Cardiol 2007; 99: 667-672.

7. Hulten E, Jackson JL, Douglas K, George S, Villines TC. The effect of early, intensive statin therapy on acute coronary syndrome: A meta-analysis of randomized controlled trials. Arch Intern Med 2006; 166: $1814-1821$.

8. Cannon CP, Braunwald E, McCabe CH, Rader DJ, Rouleau JL, Belder R, et al. Intensive versus moderate lipid lowering with statins after acute coronary syndromes. N Engl J Med 2004; 350: $1495-$ 1504.

9. Okazaki S, Yokoyama T, Miyauchi K, Shimada K, Kurata T, Sato H, et al. Early statin treatment in patients with acute coronary syndrome: Demonstration of the beneficial effect on atherosclerotic lesions by serial volumetric intravascular ultrasound analysis during half a year after coronary event: The ESTABLISH Study. Circulation 2004; 110: $1061-1068$.

10. Hiro T, Kimura T, Morimoto T, Miyauchi K, Nakagawa Y, Yamagishi $\mathrm{M}$, et al. Effect of intensive statin therapy on regression of coronary atherosclerosis in patients with acute coronary syndrome: A multicenter randomized trial evaluated by volumetric intravascular ultrasound using pitavastatin versus atorvastatin (JAPAN-ACS [Japan assessment of pitavastatin and atorvastatin in acute coronary syndrome] study). J Am Coll Cardiol 2009; 54: 293-302.

11. Bayturan O, Tuzcu EM, Lavoie A, Hu T, Wolski K, Schoenhagen P, et al. The metabolic syndrome, its component risk factors, and progression of coronary atherosclerosis. Arch Intern Med 2010; 170: $478-484$.

12. Miyauchi K, Kimura T, Morimoto T, Nakagawa Y, Yamagishi M, Ozaki Y, et al. Japan assessment of pitavastatin and atorvastatin in acute coronary syndrome (JAPAN-ACS): Rationale and design. Circ J 2006; 70: $1624-1628$

13. The Examination Committee of Criteria for Metabolic Syndrome. The definition and criteria of metabolic syndrome. J Jpn Soc Intern Med 2005; 94: 794-809 (in Japanese).

14. Rohlfing CL, Wiedmeyer HM, Little RR, England JD, Tennill A, Goldstein DE. Defining the relationship between plasma glucose and $\mathrm{HbA}(1 \mathrm{c})$ : Analysis of glucose profiles and $\mathrm{HbA}(1 \mathrm{c})$ in the Diabetes Control and Complications Trial. Diabetes Care 2002; 25: 275-278.

15. Amano T, Matsubara T, Uetani T, Nanki M, Marui N, Kato M, et al. Impact of metabolic syndrome on tissue characteristics of angiographically mild to moderate coronary lesions integrated backscatter intra- vascular ultrasound study. J Am Coll Cardiol 2007; 49: 1149-1156.

16. Alberti KG, Zimmet P, Shaw J; IDF Epidemiology Task Force Consensus Group. The metabolic syndrome: A new worldwide definition. Lancet 2005; 366: 1059-1062.

17. Yamashita S, Tsubakio-Yamamoto K, Ohama T, Nakagawa-Toyama Y, Nishida M. Molecular mechanisms of HDL-cholesterol elevation by statins and its effects on HDL functions. $J$ Atheroscler Thromb 2010; 17: 436-451.

18. Nofer JR, Kehrel B, Fobker M, Levkau B, Assmann G, von Eckardstein A. HDL and arteriosclerosis: Beyond reverse cholesterol transport. Atherosclerosis 2002; 161: 1-16.

19. Tani S, Nagao K, Anazawa T, Kawamata H, Furuya S, Takahashi H, et al. Coronary plaque regression and lifestyle modification in patients treated with pravastatin: Assessment mainly by daily aerobic exercise and an increase in the serum level of high-density lipoprotein cholesterol. Circ J 2010; 74: 954-961.

20. Ishikawa K, Tani S, Watanabe I, Matsumoto M, Furukawa K, Nomoto $\mathrm{K}$, et al. Effect of pravastatin on coronary plaque volume. Am J Cardiol 2003; 92: 975-977.

21. Connor SL, Connor WE, Sexton G, Calvin L, Bacon S. The effects of age, body weight and family relationships on plasma lipoproteins and lipids in men, women and children of randomly selected families. Circulation 1982; 65: 1290-1298.

22. Hiro T, Kimura T, Morimoto T, Miyauchi K, Nakagawa Y, Yamagishi $\mathrm{M}$, et al. Diabetes mellitus is a major negative determinant of coronary plaque regression during statin therapy in patients with acute coronary syndrome: Serial intravascular ultrasound observations from the Japan Assessment of Pitavastatin and Atorvastatin in Acute Coronary Syndrome Trial (the JAPAN-ACS Trial). Circ J 2010; 74: $1165-1174$.

23. Sipahi I, Tuzcu EM, Schoenhagen P, Wolski KE, Nicholls SJ, Balog $\mathrm{C}$, et al. Effects of normal, pre-hypertensive, and hypertensive blood pressure levels on progression of coronary atherosclerosis. J Am Coll Cardiol 2006; 48: 833-838.

24. Takashima H, Ozaki Y, Yasukawa T, Waseda K, Asai K, Wakita Y, et al. Impact of lipid-lowering therapy with pitavastatin, a new HMGCoA reductase inhibitor, on regression of coronary atherosclerotic plaque. Circ J 2007; 71: 1678-1684.

25. Nissen SE, Nicholls SJ, Sipahi I, Libby P, Raichlen JS, Ballantyne CM, et al. Effect of very high-intensity statin therapy on regression of coronary atherosclerosis: The ASTEROID trial. JAMA 2006; 295: $1556-1565$

26. Irie F, Iso H, Noda H, Sairenchi T, Otaka E, Yamagishi K, et al. Associations between metabolic syndrome and mortality from cardiovascular disease in Japanese general population, findings on overweight and non-overweight individuals: Ibaraki Prefectural Health Study. Circ J 2009; 73: 1635-1642.

27. Kasai T, Miyauchi K, Kajimoto K, Kubota N, Kurata T, Amano A, et al. The impact of pravastatin therapy on long-term outcome in patients with metabolic syndrome undergoing complete coronary revascularization. Circ J 2009; 73: 2104-2109.

28. Shiraishi J, Kohno Y, Sawada T, Nishizawa S, Arihara M, Hadase M, et al. Relation of obesity to acute myocardial infarction in Japanese patients. Circ J 2006; 70: 1525-1530.

29. Tani S, Nagao K, Anazawa T, Kawamata H, Furuya S, Takahashi H, et al. Association of body mass index with coronary plaque regression: 6-month prospective study. J Atheroscler Thromb 2009; 16: $275-282$.

30. von Birgelen C, Hartmann M, Mintz GS, van Houwelingen KG, Deppermann N, Schmermund A, et al. Relationship between cardiovascular risk as predicted by established risk scores versus plaque progression as measured by serial intravascular ultrasound in left main coronary arteries. Circulation 2004; 110: 1579-1585.

31. Dohi T, Miyauchi K, Okazaki S, Yokoyama T, Yanagisawa N, Tamura $\mathrm{H}$, et al. Early intensive statin treatment for six months improves longterm clinical outcomes in patients with acute coronary syndrome (Extended-ESTABLISH trial): A follow-up study. Atherosclerosis 2010; 210: 497-502.

32. Dohi T, Miyauchi K, Okazaki S, Yokoyama T, Yanagisawa N, Tamura $\mathrm{H}$, et al. Plaque regression determined by intravascular ultrasound predicts long-term outcomes of patients with acute coronary syndrome. J Atheroscler Thromb 2011; 18: 231-239. 